\title{
The climatic impacts of land surface change and carbon management, and the implications for climate-change mitigation policy
}

Marland, G.

Elsevier Science Ltd.

2003

Marland, G. et al. 2003. The climatic impacts of land surface change and carbon

pÿmanagement, and the implications for climate-change mitigation policy. Climate Policy 3:149 157.

http://hdl.handle.net/1975/235

Downloaded from Helda, University of Helsinki institutional repository.

This is an electronic reprint of the original article.

This reprint may differ from the original in pagination and typographic detail.

Please cite the original version. 


\section{The climatic impacts of land surface change and carbon management, and the implications for climate-change mitigation policy}

Gregg Marland ${ }^{\mathrm{a}, *}$, Roger A. Pielke, Sr. ${ }^{\mathrm{b}}$, Mike Apps $^{\mathrm{c}}$, Roni Avissar ${ }^{\mathrm{d}}$, Richard A. Betts ${ }^{\mathrm{e}}$, Kenneth J. Davis ${ }^{\mathrm{f}}$, Peter C. Frumhoff ${ }^{\mathrm{g}}$, Stephen T. Jackson ${ }^{\mathrm{h}}$, Linda A. Joyce ${ }^{\mathrm{i}}$, Pekka Kauppi ${ }^{\mathrm{j}}$, John Katzenberger ${ }^{\mathrm{k}}$, Kenneth G. MacDicken ${ }^{\text {, }}$, Ronald P. Neilson ${ }^{\mathrm{m}}$, John O. Niles ${ }^{\mathrm{n}}$, Dev dutta S. Niyogi ${ }^{\mathrm{o}}$, Richard J. Norby ${ }^{\mathrm{a}}$, Naomi Pena ${ }^{\mathrm{p}}$, Neil Sampson ${ }^{\mathrm{q}}$, Yongkang Xue ${ }^{\mathrm{r}}$

a Environmental Sciences Division, Oak Ridge National Laboratory, Bethel Valley Road, Oak Ridge, TN 37831-6335, USA

${ }^{\mathrm{b}}$ Department of Atmospheric Science, Colorado State University, Fort Collins, CO, USA

${ }^{\mathrm{c}}$ Canadian Forest Service, Natural Resources Canada, Victoria, BC, Canada

${ }^{\mathrm{d}}$ Department of Civil and Environmental Engineering, Duke University, Durham, NC, USA

${ }^{\mathrm{e}}$ Met Office, Hadley Centre for Climate Prediction Bracknell, Berkshire, UK

${ }^{\mathrm{f}}$ Department of Meteorology, Pennsylvania State University, University Park, PA, USA

${ }^{\mathrm{g}}$ Union of Concerned Scientists, Cambridge, MA, USA

${ }^{\mathrm{h}}$ Department of Botany, University of Wyoming, Laramie, WY, USA

${ }^{\mathrm{i}}$ Rocky Mountain Research Station, USDA Forest Service, Fort Collins, CO, USA

j University of Helsinki, Helsinki, Finland

${ }^{\mathrm{k}}$ Aspen Global Change Institute, Aspen, CO, USA

${ }^{1}$ Forestry Research and Development, Riau Forestry, Riau, Indonesia ${ }^{\mathrm{m}}$ USDA Forest Service, Corvallis, OR, USA

${ }^{\mathrm{n}}$ Energy and Resources Group, University of California, Berkeley, CA, USA

${ }^{\circ}$ Department of Marine, Earth, and Atmospheric Sciences, N.C. State University, Raleigh, NC, USA

p Pew Center on Global Climate Change, Arlington, VA, USA

q The Sampson Group Inc., Arlington, VA, USA

${ }^{\mathrm{r}}$ Geography Department, University of California, Los Angeles, CA, USA

Received 9 April 2002; received in revised form 14 November 2002; accepted 18 December 2002

* Corresponding author. Tel.: +1-865-241-4850; fax: +1-865-574-2232.

E-mail addresses: gum@ornl.gov (G. Marland), pielke@atmos.colostate.edu (R.A. Pielke Sr.), mapps@ nrcan.gc.ca (M. Apps), avissar@ duke.edu (R. Avissar), richard.betts@ metoffice.com (R.A. Betts), davis@ essc.psu.edu (K.J. Davis), pfrumhoff@ucsusa.org (P.C. Frumhoff), jackson@uwyo.edu (S.T. Jackson), ljoyce@ fs.fed.us (L.A. Joyce), pekauppi@mappi.helsinki.fi (P. Kauppi), johnk@agci.org (J. Katzenberger), kmacdicken@yahoo.com (K.G. MacDicken), rneilson@fs.fed.us (R.P. Neilson), joniles@socrates.berkeley.edu (J.O. Niles), dev_niyogi@ncsu.edu (D.d.S. Niyogi), rjn@ornl.gov (R.J. Norby), penan@pewclimate.org (N. Pena), rneilsampson@cs.com (N. Sampson), yxue@geog.ucla.edu (Y. Xue). 


\begin{abstract}
Strategies to mitigate anthropogenic climate change recognize that carbon sequestration in the terrestrial biosphere can reduce the build-up of carbon dioxide in the Earth's atmosphere. However, climate mitigation policies do not generally incorporate the effects of these changes in the land surface on the surface albedo, the fluxes of sensible and latent heat to the atmosphere, and the distribution of energy within the climate system. Changes in these components of the surface energy budget can affect the local, regional, and global climate. Given the goal of mitigating climate change, it is important to consider all of the effects of changes in terrestrial vegetation and to work toward a better understanding of the full climate system. Acknowledging the importance of land surface change as a component of climate change makes it more challenging to create a system of credits and debits wherein emission or sequestration of carbon in the biosphere is equated with emission of carbon from fossil fuels. Recognition of the complexity of human-caused changes in climate does not, however, weaken the importance of actions that would seek to minimize our disturbance of the Earth's environmental system and that would reduce societal and ecological vulnerability to environmental change and variability.
\end{abstract}

(C) 2003 Elsevier Science Ltd. All rights reserved.

Keywords: Climate change; Carbon sequestration; Land use change; Land surface change; Surface energy balance

\title{
1. Introduction
}

Human activity is vastly altering the Earth's vegetative cover. Such changes have considerable consequences for the health and resilience of ecosystems and for human welfare. They also contribute to anthropogenic climate change through a variety of processes. These include the growth or degradation of surface vegetation, which produces changes in the global atmospheric concentration of carbon dioxide; and changes in the land surface, which affect regional and global climate by producing changes in the surface energy budgets. These latter impacts are not currently being incorporated into the development of climate-change mitigation policies. Recent studies suggest that changes in the surface energy budgets resulting from land surface change can have a profound influence on the Earth's climate. Acknowledging the impact of changes in surface energy budgets raises the importance of treating land surface change as a component of climate change. However, it also makes it more challenging to create a system of credits and debits wherein emission or sequestration of carbon in the biosphere is equated with emission of carbon from fossil fuels or other sequestration of carbon.

The 1992 United Nations Framework Convention on Climate Change (UNFCCC) defines "climate change" as "a change of climate which is attributed directly or indirectly to human activity that alters the composition of the global atmosphere..." (UNFCCC, article 1.2, 1999). In contrast, the Intergovernmental Panel on Climate Change (IPCC) defines climate change more broadly and includes reference to land use change: "climate change refers to a statistically significant variation in either the mean state of the climate or in its variability... Climate change may be due to natural internal processes or external forcings, or to persistent anthropogenic changes in the composition of the atmosphere or in land use" (IPCC, 2001).

The elements of climate include global average surface temperature; global average sea level; the frequency, intensity, and location of extreme events; the length of the regional growing season; soil moisture; above- and below-ground biomass; local precipitation, etc. Climate change is occurring at all spatial scales from local to regional to global. Human society is currently helping to produce a global climate for which there is no precedent in the historic or prehistoric records. Given the magnitude, 
duration, and diversity of environmental changes, there is no going back-we will have to try to limit undesirable changes and to manage the changes that do occur.

International efforts to mitigate future, undesirable, climate changes have focused on the global average condition; that is, on the changes in global radiation balance caused by the increasing concentration of greenhouse gases in the atmosphere. The UNFCCC sets forth that "the ultimate objective of this Convention... is to achieve... stabilization of greenhouse gas concentrations in the atmosphere at a level that would prevent dangerous anthropogenic interference with the climate system" (UNFCCC, article 2, 1999). The Kyoto Protocol to the UNFCCC is concerned with limiting "anthropogenic carbon dioxide equivalent emissions of the greenhouse gases..." and yet, anthropogenic climate change also involves other elements of the Earth's energy balance and the internal distribution of energy within the Earth's climate system. These can be driven by land surface changes at local and regional scales; and they are quite separate from changes driven by the concentrations of greenhouse gases in the atmosphere.

With changes in land use and land cover (abbreviated as "changes in land surface" in this text), all of the elements of climate change come into play. Changes in land surface can result in emission or removal of $\mathrm{CO}_{2}$ to the atmosphere and thus to changes in the Earth's radiation balance. Changes in land surface can also change the radiation balance by altering the Earth's surface albedo. In addition, changes in land surface can alter the fluxes of sensible and latent heat to the atmosphere and thus the distribution of energy within the climate system; and in so doing can alter climate at the local, regional, and even global scale. Mitigation strategies that give credits or debits for changing the flux of $\mathrm{CO}_{2}$ to the atmosphere but do not simultaneously acknowledge the importance of changes in the albedo or in the flow of energy within the Earth's system might lead to land-management decisions that do not produce the intended climatic results.

In this paper we summarize the interactions between the land surface and the atmosphere, show why these are important to climate-change mitigation strategies, and outline some approaches whereby land-management policy can contribute to the welfare of humans and the health of ecosystems, including effects on future climates. Scientific understanding and tools are increasingly becoming available to address the broader implications of land surface interactions within the climate system for national and international policy. Finally, we note the complex issues that are raised in creating a tradeable relationship between fossil fuel emission and biosphere sequestration of carbon.

\section{Findings, evidence, examples}

Many studies have revealed the extent to which changes in the land surface have affected local and regional (multinational) climates (examples include Pielke and Avissar, 1990; Lynn et al., 1995; Henderson-Sellers, 1995; Claussen et al., 2001), and it is increasingly clear that some changes in the land surface can have significant impacts on the climate in distant parts of the Earth. Reviews of this evidence are given in Pielke (2001) and in Kabat et al. (2003). It has been long appreciated that changes in forest cover in the Amazon Basin affect the flux of moisture to the atmosphere, regional convection, and hence regional rainfall (Lean and Warrilow, 1989; Baidya Roy and Avissar, 2002). More recent work shows that these changes in forest cover have consequences far beyond the Amazon Basin (Werth and Avissar, 2002; Gedney and Valdes, 2000). Recent analyses by Lawton et al. (2001) show clearly that deforestation in Central America has negatively impacted rainfall nearby and work by Xue (1997) and others argue 
that drought in Sahelian Africa has been an important positive feedback from the destruction of regional vegetation.

Avissar and Liu (1996), Pielke (2001), Chase et al. (1996, 2000), Weaver and Avissar (2001), and Baidya Roy and Avissar (2002) and others have shown that fragmentation of the landscape can affect convective flow regimes and rainfall patterns locally and globally. Land surface changes on the order of $10 \mathrm{~km}$ on a side can cause changes in the local pattern of rainfall. The spatial scale of a disturbance that must occur in order to result in a global impact depends on where the disturbance occurs. El Nino events and land surface change simulations with climate models suggest that, in equatorial regions where towering thunderstorms are frequent, disturbing areas hundreds of kilometers on a side may yield global impacts, as discussed in Pielke (2001) and Werth and Avissar (2002). Larger areas of change would presumably be needed in other geographic locations, however the climate model experiments to test this sensitivity have not yet been performed.

Hansen et al. (1998) estimated that since the start of the industrial era (about 1750), anthropogenic changes in land cover have created a global, annual mean climate forcing of $-0.21 \mathrm{~W} / \mathrm{m}^{2}$ (with a global cooling effect of $\left.0.14^{\circ} \mathrm{C}\right)$. Betts $(2000)$ estimates the land surface forcing to be $-0.1 \mathrm{~W} / \mathrm{m}^{2}$. These compare with a global climate forcing of $1.46 \mathrm{~W} / \mathrm{m}^{2}$ from the increase in atmospheric carbon dioxide (Ramaswamy et al., 2001), with about one third of the carbon dioxide coming from the degradation of natural ecosystems. The impacts due to land surface change have not been comprehensively investigated, however; and the values for climate forcing are assigned very low confidence. The IPCC (Ramaswamy, 2001) has adopted a value of $-0.2 \pm 0.2 \mathrm{~W} / \mathrm{m}^{2}$. Most of the global cooling effect is from land surface changes at high latitudes where snow cover is frequent.

Betts (2000), among others, have raised the question whether carbon uptake by afforestation will indeed balance the effect of carbon emissions from fossil fuel and thus limit radiative forcing of climate. Betts argued that if afforestation were to be implemented at high latitude, particularly in areas with significant snow cover, the warming effect of decreased albedo could offset the cooling effect of carbon sequestration. On the other hand, Betts also noted that increasing the area of tropical forests can cool the local environment by enhancing transpiration, adding to the greenhouse gas benefit of afforestation (see also e.g. Kleidon and Heimann, 1999). These studies suggest that local, regional, and global effects of land surface changes ought to be considered in climate mitigation efforts.

The land surface is an important part of the climate system. Humans have substantially altered land cover type, ecosystem structure, natural disturbance regimes, and caused a fragmentation of the landscape. The surface cover that we see now is both the legacy of past actions and a constraint on current options. Actions taken today will, in the same way, have effects that reach far into the future.

\section{Implications for land use, land use change, and forestry in the context of climate policy}

\subsection{Limitations of existing policy initiatives}

There is a range of policy options that could be considered for recognizing the multiple and complex impacts of land surface change on the global climate system. The energy and hydrologic balances could be evaluated within a hierarchy of alternatives, with implications for emissions and sinks of greenhouse gases and for carbon management in the terrestrial biosphere. Policy makers could choose to: (1) focus efforts to limit greenhouse gas concentrations elsewhere, for example, in the energy sector, and not deal 
at all with changes in carbon stocks in the biosphere or changes in the land surface, (2) continue along the present path toward complete fungibility between carbon in or out of the atmosphere regardless of the source, (3) focus efforts on the global mean climate and the Earth's radiative balance, and treat changes in albedo similarly to changes in greenhouse gas concentrations, or (4) attempt an integrated assessment that recognizes all of the global and regional climate implications involved in a change in biosphere carbon stocks and land surface. Intermediate positions might also be chosen from this continuum of possibilities.

Option 1 echoes current thinking of some parties that mitigation efforts should focus on the most important component of increasing greenhouse gas concentrations, combustion of fossil fuels. This option clearly fails to incorporate the important climatic implications of human actions that increase or decrease carbon stocks in the biosphere and change the characteristics of the land surface.

Option 2 likewise falls short of capturing the full climatic impact of land surface change, but in focusing on carbon it does acknowledge the concern over rising greenhouse gas concentrations from all sources and that land surface change plays a role. This second alternative has the very important distinction that it is consistent with the UNFCCC, a treaty that has come into force with ratification now by over 185 countries. This alternative is also consistent with the Kyoto Protocol. (The Kyoto Protocol does not fully embrace this approach in that it imposes limits on which carbon flows in the biosphere are to be eligible for credits during the 2008-2012 first commitment period, but these limits are based on political considerations rather than on how the changes in land surface carbon stocks actually alter the climate system.) It is relatively straight forward to integrate changes in biosphere carbon stocks with accounting for emissions from other sectors and there is a developing constituency for emissions controls and emissions trading that include credit for carbon sequestration (IPCC, 2000). However, this approach assumes that increasing carbon stocks anywhere or in any way contributes equally to mitigating climate change, and this is clearly not the case.

Expanding our thinking to include all of the effects of land and carbon management on the Earth's mean climate, most notably including the effects of changing albedo, as in Option 3, would be challenging in execution. Estimating the change in albedo resulting from a change in land cover is not a simple satellite measurement. Nonetheless, changes in albedo can be expressed in terms of the Earth's radiative balance and one can envision a global warming potential (GWP) (see e.g. IPCC, 1995) factor that converts changes in albedo to an estimate of $\mathrm{CO}_{2}$ emissions equivalents. Betts (2000) makes a first attempt at this and the IPCC Third Assessment Report shows the albedo effects of land use change on the same scale of global mean radiative forcing as changes in greenhouse gas concentrations (IPCC, 2001, p. 37). There is not, of course, a one-to-one relationship between changes in biosphere carbon and changes in albedo. Biosphere carbon would have a greater effect on albedo, for example, when trees grew in snowy landscapes; and carbon taken into the biosphere would have a greater effect on albedo before canopy closure than afterward. Region-specific "discount coefficients" might be derived for a first-order attempt to adjust changes in carbon stocks according to their simultaneous effect on surface albedo and their net effect on the Earth's radiative balance. But, the full spectrum of non-linear effects resulting from changes in surface albedo (including cloud formation and feedback) is not yet well understood and this option is still somewhat speculative. More research is required to understand the change in planetary albedo that results from a landscape change.

The climatic consequences of land surface change occur at a variety of temporal scales in addition to the variety of spatial scales. Pielke (2001) discusses the spectrum of time scales associated with vegetation and soil dynamical interactions with the atmosphere and with land cover change. Vegetation phenology, 
for example, has a seasonal component associated with the annual cycle of greening and senescence while land cover change alters interactions with the atmosphere indefinitely.

\subsection{A comprehensive approach}

While anything short of Option 4 does not fully address the problem of climate changes resulting from land surface changes, it may be possible to go beyond Option 3 and develop adjustment factors for carbon accounting that approximate the full impact of land use change on the global climate, or to gradually increase the complexity of accounting as the necessary understanding and tools are developed. A critical step would be to assess the technical feasibility of determining adjustment factors to capture the global climate consequences of changing land-atmosphere interactions, taking into account regional (and ecosystem) differences and temporal variation. Experiments would likely be needed to evaluate concurrent changes in carbon stocks, albedo, evaporation, surface roughness, and transpiration; and to understand net energy balances over time. In essence these adjustment factors could serve in the same way that adjustment factors for carbon leakage are being considered (Brown et al., 2000) — that is, they could increase or decrease credits attributed to carbon sequestration to account for off-site consequences of carbon management activities.

It might even be appropriate to think of carbon management in the biosphere in terms of adjustment factors, or suitability factors, that capture other objectives of land surface change as well as carbon sequestration. These could include carbon leakage, other impacts on climate, ecosystem composition and structure, other impacts on hydrology and the environment, sustainability, and social and cultural objectives. Although this paper discusses changes in land surface entirely within the context of climate change, it is clear that changes in land surface have important considerations within other social and environmental contexts and within other international conventions. The Kyoto Protocol, for example, specifically notes that achieving mitigation objectives for climate change should be accomplished while taking into account "relevant international environmental agreements; promotion of sustainable forest management practices;" and promotion of sustainable development. Relevant international agreements include the UN Convention on Biological Diversity, the UN Convention to Combat Desertification, and the Ramsar Convention on Wetlands (IPCC, 2000, p. 114). Alternatives for carbon management, whether protection of existing ecosystems or encouragement of more carbon intensive ecosystems, can have particularly important implications for biodiversity (Huston and Marland, 2003).

To fully consider the climatic effect of changing land surface and/or managing carbon stocks in the biosphere would require complex modeling of the interactions between the atmosphere and the land surface, Option 4. An international consensus would need to consider climate impacts that are both global and regional (multinational) in scale. Effects on the climate system could be expressed in quantifiable energy units such as joule or watt $/ \mathrm{m}^{2}$, perhaps normalized for the area affected (Pielke et al., 2002). Both increases and decreases in energy flows would be recognized as impacts on the larger system. Such an accounting system could be equally rigorous, but would inevitably be more complex, than the evolving system based on tons of carbon equivalent.

Whereas climate models are not yet able to provide the analyses required for Option 4, the tools are increasingly being developed to undertake these kinds of analyses. Climate models calibrated using historical trends and information have limited predictive capacity due to the fact that environmental drivers and boundary conditions (including atmospheric chemistry and land surface cover) are significantly different from those of the past. Current models do, however, help us evaluate sensitivities and vulnerabilities, and 
these insights can be important for decision making. Current models provide the basis for evaluating the interdependencies of the factors driving climate change. Integrated analyses would allow examination of the tradeoffs and synergies between land surface and forest and cropland management based on carbon sequestration and other climatic impacts. Coping with the inherent limits to predictability in human and natural systems can be informed by science that seeks comprehensive understanding of the full range of factors involved.

There are many challenges to the development of an integrated framework for analysis. For example, modeling of climate change that considers the full climatic impact of land cover changes would need to consider a baseline condition. Would the baseline be the pre-industrial land surface, the 1990 land surface, or some other reference case? The baseline selected might, for example, result in making an important distinction between preservation of existing forest and creation of new forest. In an integrated approach, all carbon sequestration activities would not necessarily affect the factors of climate in the same way, and the differences could change over time as the ecosystems developed. In some instances, improving forest management might increase carbon stocks with little change in the other components of climate, while sequestration in soils would have a very different impact on climate than increasing above-ground carbon stocks.

The GWP is an index that allows comparison of the integrated effect of the different greenhouse gases on the Earth's radiative balance. Might this concept be expanded to include changes in the surface albedo and other elements of the Earth's surface energy balance? Having observed that local and regional changes in climate may be as important as changes in the global mean climate, we suggest that attention be given to devising a regional climate change potential (RCCP) to encapsulate the effect that specific human actions have on the redistribution of energy within the Earth's climate system.

\section{Conclusion}

There has been widespread acceptance that at some level sequestering carbon in the terrestrial biosphere has the same effect on atmospheric $\mathrm{CO}_{2}$ as does reducing emissions of $\mathrm{CO}_{2}$ (IPCC, 2000). We point out that whereas the immediate effect on atmospheric $\mathrm{CO}_{2}$ may be the same, the effect on the Earth's climate is not the same. Climate is the interaction of all of the components of the Earth's system and it includes the solar and infrared radiation and sensible and latent heat fluxes that are all impacted by changes in the Earth's surface.

Given the goal of mitigating climate change, it is important to consider our influence on all of the system components and to work toward a better representation of the full system. Present mitigation strategies focus on a single factor (greenhouse gas concentrations) and a single spatial scale (global average climate). While these provide a starting point for confronting climate change; climate change involves other factors and other scales. Humans and ecosystems reside in local climates, not in the global average climate.

Science is moving toward an integrated understanding of our climate system. How this understanding will be woven into public policy is not clear. The complexity of climate understanding requires a linkage between science and public policy so that policy can evolve as our understanding increases. The immediate question is how to minimize the vulnerability of ecosystems and human society to climate change and climate variability. To what extent do current climate-policy initiatives, focused on greenhouse gas concentrations, succeed in providing incentive for actions that reduce undesirable human influences 
on the climate system and increase resilience to climate change? The integrated perspective on climate change described here raises the importance of human-induced land cover change in global mitigation strategies, but makes comparison with other mitigation strategies more complex. Trying to make present investments in the long-term health and resilience of ecosystems, and trying to make the UN Framework Convention on Climate Change operational and consistent with its stated objectives, thus confronts a variety of complex issues.

Which actions then clearly help to prevent "dangerous anthropogenic interference in the climate system?" Reducing greenhouse gas emissions to stabilize or reduce greenhouse gas concentrations in the atmosphere and minimizing loss of existing forests, grasslands, and native ecosystems surely work to minimize human-induced climate change on all scales. We suggest that efforts to restore or mimic the structures and functions of native ecosystems will also generally be consistent with the desire to minimize the human impact on the climate system. And, there are many other environmental, economic, and social values that are important in land management choices. Recognition of the complexity of human-caused changes in climate should not be used as an excuse to avoid actions that will minimize our disturbance of the Earth's environmental system and that will decrease vulnerability to environmental change and variability. Reductions in net greenhouse gas emissions and land surface change, for example, represent appropriate approaches to lessen our impact on the environment. Our hierarchy of approaches for integrating land surface changes into climate mitigation strategies offers a significant challenge for the further integration of science and public policy.

\section{Acknowledgements}

This paper was written as part of the output from a September 2001 workshop at the Aspen Global Change Institute. We are grateful to the AGCI and its staff for the organization and conduct of this workshop and to the National Aeronautics and Space Administration, Earth Science Enterprise, for their financial support of this workshop. Acknowledgement for support of individual contributions to this work includes G.M. from the US Department of Energy's Office of Science, Biological and Environmental Research Program; R.A.P., Sr. from NASA Grants NAG8-1511 and NAG5-11370 and NSF LTER Grant DEB 96-32852; RAB from the Climate Prediction Programme of the UK Department of the Environment, Food and Rural Affairs (contract no. PECD 7/12/37); P.C.F. from the Oak Foundation and the V. Kann Rasmussen Foundation; and J.O.N. from the graduate Fund Block Grant of the University of California, Berkeley.

\section{References}

Avissar, R., Liu, Y., 1996. A three-dimensional numerical study of shallow convective clouds and precipitation induced by land-surface forcing. J. Geophys. Res. 101, 7499-7518.

Baidya Roy, S., Avissar, R., 2002. Impact of land use/land cover change on regional hydrometeorology in Amazonia. J. Geophys. Res. 107 (D20), LBA 4-1 to LBA 4-12.

Betts, R.A., 2000. Offset of the potential carbon sink from boreal forestation by decreases in surface albedo. Nature 408, 187-190.

Brown, S., Masera, O., Sathaye, J., et al., 2000. project-based activities. In: Watson, R.T., Noble, I.R., Bolin, B., Ravindranath, N.H., Verardo, D.J., Dokken, D.J. (Eds.), Land Use, Land-use Change, and Forestry, A Special Report of the Intergovernmental Panel on Climate Change. Cambridge University Press, Cambridge, UK, 377 pp. 
Chase, T.N., Peilke Sr., R.A., Kittel, T.G.F., Nemani, R.R., Running, S.W., 1996. The sensitivity of a general circulation model to global changes in leaf area index. J. Geophys. Res. 101, 7393-7408.

Chase, T.N., Peilke Sr., R.A., Kittel, T.G.F., Nemani, R.R., Running, S.W., 2000. Simulated impacts of historical land cover changes on global climate in northern winter. Clim. Dynam. 16, 93-105.

Claussen, M., Brovkin, V., Ganapolski, A., 2001. Biogeophysical versus biogeochemical feedbacks of large-scale land cover change. Geophys. Res. Lett. 28 (6), 1011-1014.

Gedney, N., Valdes, P.J., 2000. The effect of Amazonian deforestation on the northern hemisphere circulation and climate. Geophys. Res. Lett. 27 (19), 3053-3056.

Hansen, J., Sato, M., Lacis, A., Ruedy, R., Tegen, I., Mathews, E., 1998. Climate forcings in the industrial era. Proc. Natl. Acad. Sci. USA 95, 12753-12758.

Henderson-Sellers, A., 1995. Human effects on climate through the large-scale impacts of land-use change. In: Future Climates of the World: A Modeling Perspective. World Survey of Climatology, vol. 16. Elsevier, Amsterdam.

Huston, M., Marland, G., 2003. Carbon trading and biodiversity. J. Environ. Manage. 67 (1), 77-86.

IPCC, 1995. Climate Change 1994, Radiative Forcing of Climate Change and an Evaluation of the IPCC IS92 Emission Scenarios. Cambridge University Press, Cambridge, 339 pp.

IPCC, 2000. Land Use, Land-use Change, and Forestry. A Special Report of the Intergovernmental Panel on Climate Change. Cambridge University Press, Cambridge, UK, 377 pp.

IPCC, 2001. Climate Change 2001: The Scientific Basis. Contribution of Working Group I to the Third Assessment Report of the Intergovernmental Panel on Climate Change. Cambridge University Press, Cambridge, UK, $881 \mathrm{pp}$.

Kabat, P., Claussen, M., Dirmeyer, P.A., Gash, J.H.C., Bravo de Guenni, L., Meybeck, M., Pielke Sr., R.A., Vorosmarth, C.J., Hutjes, R.W.A., Sutkemeier, S. (Eds.), 2003. Vegetation, water, humans and the climate: a new perspective on an interactive system. The IGBP Series, Springer, Heidelberg, 650 pp., ISBN 3-540-42400-8.

Kleidon, A., Heimann, M., 1999. Deep-rooted vegetation, Amazonian deforestation, and climate: results from a modeling study. Global Ecol. Biogeogr. 8, 397-405.

Lawton, R.O., Nair, U.S., Pielke Sr., R.A., Welch, R.M., 2001. Climatic impact of tropical lowland deforestation on nearby montane cloud forest. Science 294, 584-587.

Lean, J., Warrilow, D.A., 1989. Simulation of the regional climatic impact of Amazon deforestation. Nature 342, $411-413$.

Lynn, B.H., Rind, D., Avissar, R., 1995. The importance of subgrid-scale mesoscale circulations generated by landscape heterogeneity in general circulation models (GCMs). J. Clim. 8, 191-205.

Pielke Sr., R.A., 2001. Influence of the spatial distribution of vegetation and soils on the prediction of cumulus convective rainfall. Rev. Geophys. 39, 151-177.

Pielke, R.A., Avissar, R., 1990. Influence of landscape structure on local and regional climate. Landscape Ecol. 4, $133-155$.

Pielke Sr., R.A., Marland, G., Betts, R.A., Chase, T.N., Eastman, J.L., Niles, J.O., Niyogi, D., Running, S.W., 2002. The influence of land-use change and landscape dynamics on the climate system-relevance to climate change policy beyond the radiative effect of greenhouse gases. Philos. Trans. A 1797, 1705-1719.

Ramaswamy, V., Boucher, O., Haigh, J., Hauglustine, D., Haywood, J., Myhre, G., Nakajima, T., Shi, G. Y., Solomon, S., 2001. Radiative forcing of climate. In: Climate Change 2001: The Scientific Basis. Contribution of Working Group I to the Third Assessment Report of the Intergovernmental Panel on Climate Change. Cambridge University Press, Cambridge, UK, pp. 349-416.

UNFCCC, 1999. United Nations Framework Convention on Climate Change; UNEP/IUC/99/2, Information Unit for Conventions, UNEP, Geneva (www.unfccc.int/resource/conv/index.html).

Weaver, C.P., Avissar, R., 2001. Atmospheric disturbances caused by human modification of the landscape. Bull. Am. Meterol. Soc. 82, 269-281.

Werth, D., Avissar, R., 2002. The local and global effects of Amazon deforestation. J. Geophys. Res. 107 (D20), LBA 55-1 to LBA 55-8

Xue, Y., 1997. Biosphere feedback on regional climate in tropical North Africa. Q. J. R. Meteorol. Soc. 123B, $1483-1515$. 